PDFlib PLOP: PDF Linearization, Optimization, Protection

Page inserted by evaluation version www.pdflib.com - sales@pdflib.com 


\section{Nursing Care for Pregnant Adolescents}

Kristen S. Montgomery

Although the physical care of pregnant adolescents is similar to that required by adult women, adolescents have additional unique needs. Adolescents often need more support and extensive teaching during pregnancy and the postpartum. Moreover, adolescents often have fewer life experiences than do adult women, making them less able to cope with the life changes they are experiencing related to pregnancy and birth. Nonjudgmental and developmentally appropriate interactions are essential to the care of pregnant adolescents. This article explores nursing care for the physical, emotional, and educational needs of adolescents during the prenatal, intrapartum, and postpartum periods. JOGNN, 32, 249-257; 2003. DOl: 10.1177/0884217503252191

Keywords: Adolescent pregnancy-Nursing care-Reproductive care

Accepted: August 2002

Every year approximately 1 million adolescents become pregnant (Henshaw, 2001). This represents about $10 \%$ of all women ages 15 to 18 years and $19 \%$ of adolescent females who have ever had sex (Alan Guttmacher Institute [AGI], 2000). Approximately $78 \%$ of adolescent pregnancies are unplanned. In 1999, the last year for which complete data are available, there were 484,794 births among adolescents 19 years of age and younger (Henshaw, 2001). About 13\% of all U.S. births are to adolescents, and $78 \%$ of these occur outside of marriage (AGI, 2000). This article addresses nursing care for adolescents during the reproductive cycle, beginning with their entry into prenatal care through the postpartum.

Adolescence represents a period of intense change for an individual. Developmentally, adolescents are trying to figure out who they are and how they fit into society. As an adolescent matures, parents become less influential and peers become increasingly influential. Peer pressure can be particularly strong. The desire to please others (particularly peers) can influence adolescents to participate in behaviors in which they might normally not be involved. During adolescence, the fallacy of invincibility predominates and is characterized by a belief that "it won't happen to me." In addition, an adolescent's concern about how others view his or her behavior (the "imaginary audience") can contribute to participation in high-risk behaviors. Late childhood and early adolescence also represent the period of time when sexual maturation begins. The combination of these developmental milestones contributes to high pregnancy rates during adolescence (Condon, Donovan, \& Corkindale, 2001; Lee, Lee, \& Chou, 2001).

\section{The Prenatal Period}

\section{Entry Into Prenatal Care}

Adolescents begin prenatal care late more often than other age groups (Gortzak-Uzan, Hallak, Press, Katz, \& Shoham-Vardi, 2001). Later entry into prenatal care may occur for several reasons. First, the adolescent may not be aware of the signs of pregnancy and therefore may not realize she is pregnant until she has missed several menstrual periods. Second, many adolescents desire to conceal their pregnancies. An adolescent may not want her parents to know she is sexually active or she may not want the father of the baby to know she has conceived.

Previous research has shown that there is a higher rate of abuse among adolescents who become pregnant (Adams \& East, 1999; Renker, 2002). An adolescent who is pregnant as a result of sexual 
abuse or rape may fear for her life if the perpetrator discovers the pregnancy. An adolescent also may fear that she will lose her job or friends, be removed from school or home, or suffer other negative consequences. In addition, she may fear the stigmatization that often occurs among adolescents who become pregnant.

When the pregnancy is unintended, adolescents may experience extreme anguish in deciding what to do. The adolescent may experience guilt, depression, denial, feelings of being trapped, a sense of inadequacy, or just being overwhelmed. Preoccupation with these emotions may contribute to delayed entry into prenatal care (Hart \& Fishel, 1998). These factors can also contribute to an adolescent's desire to hide her pregnancy. However, in some instances adolescents do receive positive validation for their pregnancy from peers.

Once an adolescent decides to seek care or is told by someone that she should seek care, she may not know where to go for care or that programs exist for adolescents who cannot afford to pay (Baker, 1996). Adolescents may also find that services are not comprehensive and may lack transportation and child care options (Hart \& Fishel, 1998). Information hotlines and Web sites such as http://www.teenadvice.org are ways to provide this information to adolescents.

\section{revious research has shown that there is a higher rate of abuse among adolescents who become pregnant.}

Pregnant adolescents who sought prenatal care early were more likely to have adequate family support, were not afraid to tell their parents about the pregnancy, and had more knowledge about pregnancy than those who delayed entry into prenatal care (Lee \& Grubbs, 1995). Wiemann, Berenson, Pino, and McCombs (1997) evaluated risk factors for late entry into prenatal care among adolescents younger than 18 years. They found that adolescents who no longer had contact with the father of their baby were 4.2 times as likely as those who maintained contact to enter prenatal care after the 1 st trimester. In addition, adolescents without a history of abortion, those who had not used alcohol during the last 30 days, those with only one sex partner in the last 12 months, those with less education, and those who were unemployed were also more likely to initiate prenatal care late (Weimann et al., 1997). It may be that adolescents who perceive themselves as healthy or having less risk might not see as great a need to initiate prenatal care as those who have identifiable risk factors.
Petersen and Alexander (1992) found that more adolescent pregnancies occurred during the end of the school year and that these adolescents tended to seek prenatal care later because fewer resources were available to them during the summer months. It is also likely that when school was not in session, fewer trusted adults were available to talk to about issues such as where to go for care and why prenatal care was important. Stevens-Simon, Roghmann, and McAnarney (1991) found that more adolescents than adults reported early 1 st trimester vaginal bleeding that they attributed to menses, which may have contributed to their delay in seeking prenatal care.

\section{Pregnant Adolescents' Needs}

Developmental Needs. The first prenatal visit represents a monumental step for the pregnant adolescent. Entry into prenatal care represents the beginning of her new life. The adolescent should be praised for beginning prenatal care, particularly if it is in the 1st trimester. The importance of prenatal care and taking care of oneself during pregnancy should be emphasized. Adolescents who have decided to continue a pregnancy will need significant emotional support throughout the pregnancy. Emotional support and prenatal care content must be tailored to the individual adolescent's needs; developmental level; and individual, racial, or cultural preferences (Raines \& Morgan, 2000). Drake (1996) reported that careful assessment of an adolescent's developmental level is critical to providing appropriate care during pregnancy and beyond. She noted that because chronological age does not always represent maturity level, additional developmental assessment may be needed.

Early adolescence can be defined as the period between 11 and 15 years (Drake, 1996). Early adolescents are dependent on their families for emotional and physical support and often need assistance with health care decisions. Adolescents in this phase of life are often presentoriented and self-centered. Because of this orientation, it is useful for the nurse to focus on how an adolescent's behaviors influence her health now, rather than placing emphasis on future expectations (Drake, 1996). Simple language and visual representation of concepts can also be useful during this phase. Typically, young adolescents are not seeking to be sexually active; thus, it is important for the nurse to assess for a history of abuse or coercion (Drake, 1996).

Middle adolescence is defined as the period between 14 and 18 years. During middle adolescence, the individual begins developing more abstract thinking and may be able to understand consequences of current behaviors for later outcomes (Drake, 1996). The nurse should anticipate that the pregnant adolescent at this age will have many questions but may be reluctant to ask them due to inadequate or underdeveloped communication skills. Promoting an 
environment of trust and caring can encourage the adolescent to ask questions and express concerns she may have.

Late adolescence is defined as 17 to 20 years of age. At this stage, adolescents have usually mastered abstract thinking and are able to understand and predict future consequences of current actions (Drake, 1996). The pregnant adolescent at this stage is more likely to be a capable and active participant in health care decisions.

Physical Care Needs. Adolescents' physical care needs during the antepartum are similar to those of adult women. The Centers for Disease Control and Prevention (CDC, 2002) recommends that all adolescents who engage in high-risk behaviors be screened for sexually transmitted infections (especially gonorrhea, syphilis, and Chlamydia) during the 1 st trimester and prior to 36 weeks gestation. Pregnant adolescents also should receive a thorough nutritional assessment and follow-up counseling to improve their nutritional intake. The nutritional assessment should include dietary assessment, weight and height evaluation, and laboratory testing. Dietary assessment should include dietary practices and patterns to determine adequacy of food intake and should also include an assessment of the food resources available to the adolescent. Weight and height assessment should determine the adolescent's body mass index and pattern of pregnancy weight gain. A laboratory assessment of hemoglobin and hemocrit to assess for anemia and additional laboratory tests can be used to determine inadequacies in any of the micronutrients or electrolytes (Story \& Stang, 2000).

The adolescent should be monitored to ensure that the pregnancy is progressing normally and for any complications that may develop. Adolescents have been found to be at higher risk than adult women for some complications of pregnancy. They are at particular risk for pregnancy-induced hypertension, preeclampsia, and intrauterine growth restriction (Orvos et al., 1999); preterm delivery and low birth weight (Abu-Heija, Ali, \& Al-Dakheil, 2002; Gortzak-Uzan et al., 2001; KoniakGriffin \& Turner-Pluta, 2001); and inadequate weight gain (Dubois, Coulombe, Pencharz, Pinsonneault, \& Duquette, 1997). Infants born to adolescent mothers have a higher rate of death in the 1st year of life, particularly infants of mothers who are younger than 15 years at the time of delivery (Phipps, Blume, \& DeMonner, 2002). Careful monitoring of adolescents for signs and symptoms of problems will assist the health care provider to begin treatment early, with the potential for improved outcomes.

Educational Needs. The adolescent's educational needs during the antepartum are often great. The content of prenatal education should be covered slowly and written materials provided for the adolescent to keep as a reference. Early in the prenatal period, adolescents often need information about eating well during pregnancy, normal fetal growth and development, body changes associated with pregnancy, common ailments and how to resolve or treat them safely during pregnancy, and general safety during pregnancy (e.g., seat belt use) (Hart \& Fishel, 1998). Depending on the time of the adolescent's entry

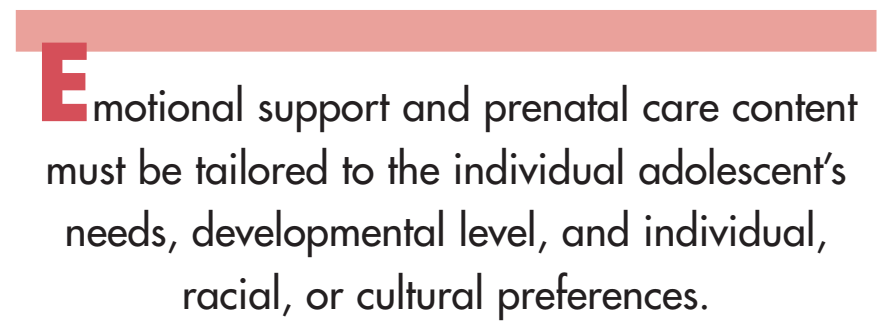

into prenatal care, these topics can be covered earliest, with a later focus on labor and delivery, care of the newborn in the first days at home, postpartum care and followup, and expectations for the 1st year of life.

It is important, however, to focus on the adolescent's current needs. If the adolescent has burning questions about labor and delivery or another issue, she may not be able to focus on other content until those issues are resolved. Providing information as it is needed can reinforce learning and reduce anxiety. Whenever possible, written materials should also be provided for reinforcement. Written materials that were developed for adolescents can be especially useful. They should be appropriate for the adolescent's educational level so that the adolescent does not view them as "babyish" or that she is receiving care that is different from that provided to others. Adolescents who participated in a study about prenatal nutrition education noted that they preferred adolescent actresses in electronic or video mechanisms to written materials (Skinner, Carruth, Ezell, \& Shaw, 1996).

If the adolescent brings a family member or other support person to prenatal appointments, that person should also be actively involved in the educational process (Roye $\&$ Balk, 1997). Including the adolescent's support person demonstrates respect for the adolescent. By participating in the educational process, the support person will be able to provide support and positive reinforcement for the adolescent. Paskiewicz (2001) noted that strengthening the mother-daughter relationship between the adolescent and her mother could add benefit and strengthen negotiation of child care activities, improve communication, and enhance education of infant stimulation and developmental needs. Resources for additional information can also be provided. 


\section{Comprehensive Programs}

Roye and Balk (1996, 1997) found that adolescent mothers who participated in a prenatal and parenting program with their own mothers were less likely to drop out of school and had better self-esteem when compared with those not in the program. Similarly, Paskiewicz (2001) found that the mother-daughter relationship was valuable in assisting the pregnant adolescent to care for herself during the pregnancy and postpartum. Paskiewicz recommended that the nursing assessment include an evaluation of this relationship early in the prenatal period to promote the best outcomes.

Koniak-Griffin et al. (2002) examined the effects of an early intervention program for adolescent mothers that included preparation for motherhood classes and individual home visits during pregnancy and through 1 year postpartum. Public health nurses who worked in the county health department made the visits. Participants in this program were mostly Latina (64\%) and African American $(11 \%)$ and were from impoverished backgrounds. Compared to control subjects who received routine follow-up, infants of mothers who participated in this program had fewer total days of hospitalization and episodes of illness during the 1st year of life (Koniak-Griffin et al., 2002). There was also a positive effect on immunization rates. The rate of substance use (alcohol, tobacco, and marijuana) increased from pregnancy through the 1st postpartum year among both groups but was lower among the mothers who participated in the intervention.

Stevens-Simon, Nelligan, and Kelly (2001) conducted a study to determine if adding an intensive home visitation component to a comprehensive adolescent-focused maternity program would prevent child abuse and neglect, which some investigators have found occurs at a higher frequency among adolescent mothers. The study included 171 participants who were considered at high risk for child abuse and neglect. The authors found that adherence to the home visits varied in relation to the support the adolescent mother received from her family and the father of her baby (Stevens-Simon et al., 2001). No significant differences were found in health care utilization, rate of postpartum return to school, repeat pregnancies, or child abuse and neglect. In this sample, the rate of maltreatment rose in conjunction with the predicted risk of the mother.

Olds and Korfmacher (1997) developed a comprehensive home visitation program for low-income, pregnant White women in rural New York. Public health nurses began individualized services in the 2 nd trimester and continued through the infant's 2 nd birthday. Specific visitation protocols were developed and followed every week until the baby's birth, weekly for the first 6 weeks, twice a month until the 21st postpartum month, and then monthly until the child's 2 nd birthday. Prenatal visits focused on behavior changes to improve pregnancy outcomes (nutrition, smoking and substance use cessation, signs and symp- toms of pregnancy complications, such as urinary tract infections, sexually transmitted infections, and hypertension). Postnatal visits focused on infant care, such as signs of illness, temperature taking, communication, and motherinfant interaction, including responding to cues, household safety, emotional and cognitive development, and follow-up care. This model was developed as an adjunct to regular prenatal care. Outcomes included decreased maternal smoking, reduced birth of preterm infants, improved birth weight, and decreased child abuse. Because of the success of this model, it is being implemented in a variety of cities across the United States.

Another model program, developed by Koniak-Griffin, Mathenge, Anderson, and Verzemnieks (1999), focused on early intervention with pregnant Latina and African American adolescents. This program also included home visits by public health nurses and preparation-for-motherhood classes that began late in pregnancy and continued until the child's 1 st birthday. Seventeen home visits were included, and each typically lasted 2 to 2.5 hours. The public health nurses focused on self-care during pregnan$\mathrm{cy}$, use of health care services, signs and symptoms of preterm labor and other complications, reduction of substance abuse, emotional support, anticipatory guidance for maternal role development transitions after the birth, and planning for school completion (Koniak-Griffin et al., 1999). Postpartum visits focused on infant care, selfcare, and family planning. Nursing interventions addressed effective communication and problem-solving skills and life planning. Adolescent mothers who participated in this program had decreased total hospital days for infants following discharge, improved immunization rates, and improved maternal educational status when compared with control group mothers. Although each of these model programs has been successful in the sample population, Koniak-Griffin and Turner-Pluta (2001) warned that further research is necessary before widespread implementation occurs, including multisite replication with varying ethnic and racial groups and comprehensive, long-term follow-up.

\section{Nursing Response to Social Risks Common in Pregnant Adolescents}

Pregnant adolescents experience higher rates of certain social problems when compared with older women. Two of the most significant problems are domestic violence and substance abuse.

Domestic Violence. Renker (2002) interviewed 40 pregnant adolescents regarding their abuse experiences the year before and during their current pregnancy. Themes that emerged from these qualitative interviews included seeking safety, losing faith in authorities designed to protect them, substance abuse concerns, developmental progression, suicide attempts, and changing and temporary relationships (Renker, 2002). Because 
abuse rates were found to be elevated in the adolescent population, Renker recommended routine screening for abuse during prenatal care that includes questions about past pregnancies and multiple perpetrators. She also recommended that a developmental framework be used when planning safety and advocacy interventions for the adolescent who is experiencing abuse.

Physical abuse during adolescent pregnancy can result in complications for both the mother and the fetus/infant (Renker, 2002). Infants born to mothers abused during pregnancy often weigh less than average and may be classified as low birth weight. Pregnant adolescents who are experiencing abuse are more likely to abuse substances, receive inadequate prenatal care, and have lower pregnancy weight gain when compared with those who are not abused (Campbell, Poland, Waller, \& Ager, 1992; Curry, Doyle, \& Gilhooley, 1998; Gazmararian et al., 2000; McFarlane, Parker, \& Soeken, 1996; Renker, 1999).

Substance Abuse. The Office of Technology Assessment (1991) listed drug and alcohol abuse, anxiety, depression, self-esteem problems, rebelliousness, and suicide as significant problems among pregnant adolescents. Pregnant adolescents who experienced violence were more likely to use cigarettes, alcohol, and illicit drugs when compared with those who did not experience violence (Martin, Clark, Lynch, Kupper, \& Cilenti, 1999; Quinlivan $\&$ Evans, 2001). Substance use during pregnancy can contribute to low birth weight and prematurity as well (Kelly et al., 2002).

For pregnant adolescents who smoke, various programs can be recommended. Albrecht, Higgins, and Lebow (2000) found that pregnant adolescents who participated in a Teen FreshStart program or Teen FreshStart with Buddy program had higher knowledge levels when compared with a control group who received standard care. In this study, adolescents with greater knowledge postintervention and greater increases in knowledge quit smoking at higher rates than those with less knowledge. Higgins, Alessi, and Dantona (2002) found that voucher-based incentives were a promising intervention for substanceabusing adolescents and recently postpartum women.

Because of these social risks to pregnant adolescents, social service follow-up is commonly needed. Family problems and housing needs may also warrant close follow-up by a social worker. Many comprehensive adolescent pregnancy clinics provide nutritional and social services on site. Ideally, the same social worker can continue followup through the postpartum year as well.

\section{The Intrapartum Period}

Adolescents may enter the intrapartum period wellprepared for labor and birth or not prepared at all. Prepa- ration most often depends on the time of entry into prenatal care. Adolescents who began prenatal care earlier are more likely to have had ample opportunity to absorb information related to labor and birth. In addition, the more prenatal care visits they have attended, the more likely it is that they received some content related to labor and birth. Prenatal care attendance also increases the likelihood that they were encouraged to attend childbirth classes. Attendance at childbirth classes, although not as common among adolescents, greatly enhances a woman's ability to cope with labor and significantly increases her knowledge of what to expect during the birth process.

\section{Physical Needs During the Intrapartum Period}

The physical needs of the adolescent in labor are similar to the needs of adult women (Treffers, Olukoya, Ferguson, \& Liljestrand, 2001). From a physical perspective, adolescents are mostly healthy and may be in better physical shape than many adult women. Additionally, because of their youth, adolescents may also be more flexible physically and may have fewer stereotypes of what labor and delivery should be like. Because of their increased physical condition and youth, they may have better stamina for pushing and may be able to assume various positions that facilitate birth. Although these characteristics emphasize the positive aspects of an adolescent's youth, adolescents may also be more modest, which can interfere with birth. Very young adolescents, particularly those 15 years or younger, may be at risk for cephalopelvic disproportion because of their immature body structure, making cesarean delivery necessary; however, older adolescents are generally at less risk than adult women (Ambadekar, Khandait, Zodpey, Kasturwar, \& Vasudeo, 1999; PavlovaGreenfield, Sutija, \& Gudavalli, 2000). Because adolescents have less life experience, they may also have fewer resources to cope with labor and delivery. Many adolescents do not tolerate pain well and may need anesthesia and analgesia. They may not be able to concentrate or may not wish to concentrate on breathing or relaxation techniques as many of them have grown up within a generation of convenience and expect instant gratification of their (pain management) needs. Active labor is not the time to explore these issues; pain control and adequate maternal coping with labor are necessary to promote positive maternal and fetal outcomes. Maternal-infant attachment may also be facilitated by a positive birth experience (Mercer, 1985; Walker \& Montgomery, 1994).

\section{Emotional and Educational Needs During the Intrapartum Period}

Adolescents have many emotional needs during the intrapartum period (Treffers et al., 2001). Adolescents may have an intense fear of pain and worry about how they will manage life after the baby arrives. Because many 
adolescents are not future oriented, they may not have addressed these issues previously. Adolescents may also fear needles, the hospital environment, "splitting open" during the birth, and medical personnel. These issues can be further intensified if the adolescent does not have a support person present or if a present support person is inadequate.

Many adolescents have supportive mothers or other female relatives who can help them through the birth process. However, a number of adolescents rely on boyfriends or the father of the baby, who is often young and inexperienced. The partner who is present to provide emotional support may be ill-prepared for this role unless specific structured information was given or formal child-

\section{trave he adolescent mother needs to have the knowledge and skills to care for her own newborn, even if the grandmother will be an active caregiver.}

birth classes were taken. Both of these options are relatively infrequent for most adolescent couples.

The nurse can provide instruction to the support person who is present and can help by setting a positive example that includes providing emotional support to the mother. Any instruction given to a support person for the first time during labor needs to be specific and concrete, as they are often anxious themselves and may not be able to comprehend detailed information. Instruction to an inexperienced support person can include statements like "help her to sit up/turn on her side/go to the bathroom" or "here is a cool cloth for her forehead." Statements such as these are clear and provide specific direction so the individual does not need to think about how to get something done or where to look for materials. Individuals not familiar with hospital environments are often confused and fear that they might disturb the delicate order of the setting. Thus, they may need direction to complete simple tasks. If the nurse assumes most of the physical care related to the laboring adolescent, the support person has more time available to attend to the mother's emotional needs. The nurse should also continue to provide emotional care to the adolescent and her support person.

Fear of the labor and birth process can be alleviated to some extent by providing the adolescent with brief and simple descriptions of what to expect and what is happening. If there is time during admission to the labor and delivery unit, the adolescent should be given an overview of what to expect during the birth process. Providing this information early will allow the adolescent to assimilate the content and will help her to know what is happening during the process. The nurse will be more likely to have the adolescent's full attention prior to active labor. In addition, providing information early will set the stage to build a trusting relationship and keep anxiety levels low. However, the nurse should keep in mind that the adolescent and her support person will need frequent reminders of what will happen next. Labor and delivery is a time of heightened anxiety, and it is likely that instructions will be forgotten over the course of time.

Adolescents, as well as adult women, should be told everything that is happening to them before it actually happens. Even in the event of an emergency, the adolescent needs to be kept informed of her health status. Although this is not completely the nurse's responsibility, the nurse can set a positive example for other health care providers. For example, the adolescent needs to be told before she has an internal examination that it will be done. Often the physician communicates this information to the nurse but not to the patient. In instances such as these, the nurse can communicate this information to the patient. Communicating in this way can help set the stage for open communication among all health care providers and the patient for the remainder of the adolescent's labor and delivery experience.

\section{The Postpartum Period}

Like the intrapartum period, the postpartum period is often overwhelming for the new adolescent mother. Many adult mothers are overwhelmed with this life transition; thus, adolescents are at particular risk during this time period as they have fewer resources and life experiences to cope with stressful life periods. They may also have less experience caring for or being around infants and young children.

\section{Physical Needs During the Postpartum}

The physical needs of the postpartum adolescent are similar to those of adult women. The young adolescent may have a more extensive episiotomy or tear and will need appropriate relief measures. However, because of her youth, the adolescent may experience a quicker recovery and healing time.

\section{Emotional Needs During the Postpartum}

The emotional needs of a postpartum adolescent can be significant. The adolescent will need general emotional support for her new role as any new mother does, but adolescents generally have additional needs. These needs include addressing potential family conflicts related to the birth and who will assume care of the child, return to school, finances, child care while the adolescent mother works/attends school, and similar issues. The adolescent should be supported as she explores these issues in the 
early postpartum period. Resolution of such conflicts and an initial plan will benefit all involved. The family is an extremely important source of financial and emotional support for the adolescent mother, and every effort should be made to preserve a healthy family environment, as few adolescent mothers will be able to survive without familial support and resources (Roye \& Balk, 1997).

In addition to potential family issues, the adolescent may be overwhelmed with her new responsibilities. Offering encouragement and support will help the adolescent assume her maternal role. Simple instructions and opportunities to practice caring for her newborn can help her to learn these new responsibilities. Resources for additional sources of support are also needed. New mother support groups, adolescent mother support groups, and breastfeeding support groups can be especially useful. Helping the adolescent set realistic goals for the future and successfully integrate the newborn into her life can make a tremendous difference in ensuring the adolescent has a successful transition to motherhood (Condon et al., 2001).

\section{Postpartum Teaching Needs \\ for the New Adolescent Mother}

Despite the fact that they have given birth, adolescents may still not have a clear understanding of reproductive processes. Knowledge of anatomy and physiology is often vague, and the adolescent mother may need clarity to understand how to care for herself appropriately during the postpartum period. She will need simple instructions, and diagrams may be useful to illustrate points, especially for episiotomy care and Kegel exercises. Because this is often a stressful and overwhelming experience for the adolescent, the nurse should plan to repeat instructions often and reinforce content during the adolescent's postpartum hospital stay. Adolescents who receive extensive prenatal instruction may retain some knowledge, but will certainly need reminders and reinforcement teaching. Ample opportunity to practice new skills (e.g., diapering, feeding) is essential.

The nurse should not assume caregiving for the infant, nor should the nurse allow the newborn's grandmother to assume full responsibility (American Academy of Pediatrics [AAP], 2001). The adolescent mother needs to have the knowledge and skills to care for her own newborn even if the grandmother will be an active caregiver (AAP, 2001). At times it can be a delicate balance between what the grandmother and the new mother wish. One must be careful not to let an overbearing grandparent "take over" care of the newborn, which can result in feelings of inadequacy and unimportance in the adolescent mother. For adolescents who are not able to care for their infants because of these types of situations, an additional pregnancy often follows in hopes that she will be able to care for the next baby (East \& Felice, 1996). Successive pregnancies without adequate spacing can predispose the adolescent mother to a multitude of physiological and social complications. Although in some cultures it is the expectation by both the adolescent mother and the grandmother that the grandmother will initially assume care for the newborn, it is important that there is consensus on this issue and that the adolescent is supported at this stressful time. However, even if the grandmother will provide this initial care, the adolescent mother must have knowledge of how to care for her newborn before being discharged from the hospital (NAACOG/AWHONN, 1991).

\section{Summary}

Physical care of the pregnant and postpartum adolescent is similar to that of adult women. However, adolescents often need additional support and teaching during pregnancy and the postpartum. Adolescents may have fewer life experiences than adult women, making them less able to cope with the life changes they are going through related to pregnancy and birth. Nonjudgmental care and simple instructions are essential to caring for the pregnant adolescent during the reproductive cycle.

\section{RESOURCES FOR ADDITIONAL INFORMATION}

Hofferth, S. L., Reid, L., \& Mott, F. L. (2001). The effects of early childbearing on schooling over time. Family Planning Perspectives, 33, 259-267.

Jimenez, M. A., Martin, A. R., \& Garcia, J. R. (2000). Comparing the biological and psychosocial risks of pregnancy between groups of adolescents and adults. European Journal of Epidemiology, 16, 527-532.

O'Sullivan, A. L. (1999). Adolescent pregnancy and parenting. In J. J. Fitzpatrick \& K. S. Montgomery (Eds.), Maternal child health nursing research digest. New York: Springer.

Story, M., \& Stang, J. (Eds.). (2000). Nutrition and the pregnant adolescent: A practical reference guide. Minneapolis: Center for Leadership, Education, \& Training in Maternal and Child Nutrition, Public Health Nutrition, Division of Epidemiology, School of Public Health, University of Minnesota. Retrieved from http://www.epi.umn.edu/let/ nmpabook.html

Swan, L. L., \& Apgar, B. S. (1995). Preconceptual obstetric risk assessment and health promotion. American Family Physician, 51, 1875-1885, 1888-1890.

\section{WEB SITES}

Minnesota Organization on Adolescent Pregnancy Prevention and Parenting: http://www.moapp.org

National Organization on Adolescent Pregnancy, Parenting, and Prevention: http://www.noapp.org

Resource Center for Adolescent Pregnancy Prevention: http:// www.etr.org/recapp/ 


\section{REFERENCES}

Abu-Heija, A., Ali, A. M., \& Al-Dakheil, S. (2002). Obstetrics and perinatal outcome of adolescent nulliparous pregnant women. Gynecologic and Obstetric Investigation, 53, 9092.

Adams, J. A., \& East, P. L. (1999). Past physical abuse is significantly correlated with pregnancy as an adolescent. Journal of Pediatric and Adolescent Gynecology, 12, 133-138.

Alan Guttmacher Institute. (2000). Facts in brief: Teen sex and pregnancy. Retrieved from http://www.agi-usa.org/pubs/ fb_teen_sex.html

Albrecht, S. A., Higgins, L. W., \& Lebow, H. (2000). Knowledge about the deleterious effects of smoking and its relationship to smoking cessation among pregnant adolescents. Adolescence, 35, 709-716.

Ambadekar, N. N., Khandait, D. W., Zodpey, S. P., Kasturwar, N. B., \& Vasudeo, N. D. (1999). Teenage pregnancy outcome: A record based study. Indian Journal of Medical Science, 53, 14-17.

American Academy of Pediatrics Committee on Adolescence and Committee on Early Childhood, Adoption, and Dependent Care. (2001). Care of adolescent parents and their children. Policy statement RE0020. Pediatrics, 107, 429-434. Retrieved from http://www.aap.org/policy/re0020. html

Baker, T. J. (1996). Factors related to the initiation of prenatal care in the adolescent nullipara. Nurse Practitioner, 21(2), 26-42.

Campbell, J. C., Poland, J. L., Waller, J. B., \& Ager, J. (1992). Correlates of battering during pregnancy. Nursing Research, 38, 18-24.

Centers for Disease Control and Prevention. (2002). Sexually transmitted diseases treatment guidelines 2002. Morbidity \& Mortality Weekly Reports, 51(RR-6), 5-7.

Condon, J. T., Donovan, J., \& Corkindale, C. J. (2001). Australian adolescents' attitudes and beliefs concerning pregnancy, childbirth and parenthood: The development, psychometric testing and results of a new scale. Journal of Adolescence, 24, 729-742.

Curry, M. A., Doyle, B. A., \& Gilhooley, J. (1998). Abuse among pregnant adolescents: Differences by developmental age. MCN: American Journal of Maternal Child Nursing, 23, 144-150.

Drake, P. (1996). Addressing developmental needs of pregnant adolescents. Journal of Obstetric, Gynecologic, and Neonatal Nursing, 25, 518-524.

Dubois, S., Coulombe, C., Pencharz, P., Pinsonneault, O., \& Duquette, M. P. (1997). Ability of the Higgins Nutritional Intervention Program to improve adolescent pregnancy outcome. Journal of the American Dietetic Association, 97, 871-878.

East, P. L., \& Felice, M. E. (1996). Adolescent pregnancy and parenting: Findings from a racially diverse sample. Mahwah, NJ: Lawrence Erlbaum.

Gazmararian, J. A., Petersen, R., Spitz, A. M., Goodwin, M. M., Saltzman, L. E., \& Marks, J. S. (2000). Violence and reproductive health: Current knowledge and future directions. Maternal Child Health Journal, 4(2), 79-83.
Gortzak-Uzan, L., Hallak, M., Press, F., Katz, M., \& ShohamVardi, I. (2001). Teenage pregnancy: Risk factors for adverse perinatal outcome. Journal of Maternal Fetal Medicine, 10, 393-397.

Hart, A. L., \& Fishel, A. H. (1998). Intervening with teen mothers: A case study. Journal of the American Psychiatric Nurses Association, 4, 18-23.

Henshaw, S. K. (2001). U.S. teenage pregnancy statistics with comparative statistics for women aged 20-24. The Alan Guttmacher Institute. Retrieved from http:/www.agi-usa. org/pubs/teen_preg.pdf

Higgins, S. T., Alessi, S. M., \& Dantona, R. L. (2002). Voucherbased incentives. A substance abuse treatment innovation. Addictions \& Behavior, 27, 887-910.

Kelly, R. H., Russo, J., Holt, V. L., Danielsen, B. H., Zatzick, D. F., Walker, E., et al. (2002). Psychiatric and substance use disorders as risk factors for low birth weight and preterm delivery. Obstetrics \& Gynecology, 100, 297-304.

Koniak-Griffin, D., Anderson, N. L., Brecht, M. L., Verzemnieks, I., Lesser, J., \& Kim, S. (2002). Public health nursing care for adolescent mothers: Impact on infant health and selected maternal outcomes at 1 year postbirth. Journal of Adolescent Health, 30, 44-54.

Koniak-Griffin, D., Mathenge, C., Anderson, N. L. R., \& Verzemnieks, I. (1999). An early intervention program for adolescent mothers: A nursing demonstration project. Journal of Obstetric, Gynecologic, and Neonatal Nursing, 28, 51-59.

Koniak-Griffin, D., \& Turner-Pluta, C. (2001). Health risks and psychosocial outcomes of early childbearing: A review of the literature. Journal of Perinatal and Neonatal Nursing, 15(2), 1-17.

Lee, M. C., Lee, S. H., \& Chou, M. C. (2001). Association of risk-taking behaviors with adolescent childbearing. Journal of the Formosa Medicine Association, 100, 533-538.

Lee, S., \& Grubbs, L. (1995). Pregnant teenagers' reasons for seeking or delaying prenatal care. Clinical Nursing Research, 4, 38-49.

Martin, S. L., Clark, K. A., Lynch, S. R., Kupper, L. L., \& Cilenti, D. (1999). Violence in the lives of pregnant teenage women: Associations with multiple substance use. American Journal of Drug and Alcohol Abuse, 25, 425-440.

McFarlane, J., Parker, B., \& Soeken, K. (1996). Abuse during pregnancy: Associations with maternal health and infant birth weight. Nursing Research, 42, 37-42.

Mercer, R. T. (1985). Relationship of the birth experience to later mothering behaviors. Journal of Nurse-Midwifery, 30, 204-210.

Nurses' Association of the American College of Obstetricians and Gynecologists. (1991). Standards for the nursing care of women and newborns (4th ed.). Washington, DC: NAACOG.

Office of Technology Assessment, U.S. Congress. (1991). Pregnancy and parenting: Prevention and services. In Adolescent health: Vol. 2 Background and effectiveness of selected prevention and treatment services (pp. 325-427). Washington, DC: Author.

Olds, D., \& Korfmacher, J. (1997). The evolution of a program of research on prenatal and early childhood home visita- 
tion: Special issue introduction. Journal of Community Psychology, 25, 1-7.

Orvos, H., Nyirati, I., Hajdu, J., Pal, A., Nyari, T., \& Kovacs, L. (1999). Is adolescent pregnancy associated with adverse perinatal outcome? Journal of Perinatal Medicine, 27, 199-203.

Paskiewicz, L. S. (2001). Pregnant adolescents and their mothers: A shared experience of teen mothering. MCN: American Journal of Maternal Child Nursing, 26, 33-38.

Pavlova-Greenfield, T., Sutija, V. G., \& Gudavalli, M. (2000). Adolescent pregnancy: Positive perinatal outcome at a community hospital. Journal of Perinatal Medicine, 28, 443-446.

Petersen, D. J., \& Alexander, G. R. (1992). Seasonal variation in adolescent conceptions, induced abortions, and late initiation of prenatal care. Public Health Reports, 107, 701706.

Phipps, M. G., Blume, J. D., \& DeMonner, S. M. (2002). Young maternal age associated with increased risk of postneonatal death. Obstetrics \& Gynecology, 100, 481-486.

Quinlivan, J. A., \& Evans, S. F. (2001). A prospective cohort study of the impact of domestic violence on young teenage pregnancy outcomes. Journal of Pediatric \& Adolescent Gynecology, 14, 17-23.

Raines, D. A., \& Morgan, Z. (2000). Culturally sensitive care during childbirth. Applied Nursing Research, 13, 167172.

Renker, P. R. (1999). Physical abuse, social support, self-care, and pregnancy outcomes of older adolescents. Journal of Obstetric, Gynecologic, and Neonatal Nursing, 28, 377388.

Renker, P. R. (2002). "Keep a blank face. I need to tell you what has been happening to me." MCN: American Journal of Maternal Child Nursing, 27, 109-116.

Roye, C. F., \& Balk, S. J. (1996). Evaluation of an intergenerational program for pregnant and parenting adolescents. Maternal Child Nursing Journal, 24, 32-40.

Roye, C. F., \& Balk, S. J. (1997). Caring for pregnant teens and their mothers, too. MCN: American Journal of Maternal Child Nursing, 22, 153-157.
Skinner, J. D., Carruth, B. R., Ezell, J. M., \& Shaw, A. (1996). How and what do pregnant adolescents want to learn about nutrition? Journal of Nutrition Education, 28, 266271.

Stevens-Simon, C., Nelligan, D., \& Kelly, L. (2001). Adolescents at risk for mistreating their children. Part II: A home- and clinic-based prevention program. Child Abuse and Neglect, 25, 753-769.

Stevens-Simon, C., Roghmann, K. J., \& McAnarney, E. R. (1991). Early vaginal bleeding, late prenatal care, and misdating in adolescent pregnancies. Pediatrics, 87, 838840.

Story, M., \& Stang, J. (2000). Nutrition assessment of pregnant adolescents. In M. Story \& J. Stang (Eds.), Nutritional and the pregnant adolescent: A practical reference guide (pp. 63-80). Minneapolis: Center for Leadership, Education, and Training in Maternal and Child Nutrition, University of Minnesota.

Treffers, P. E., Olukoya, A. A., Ferguson, B. J., \& Liljestrand, J. (2001). Care for adolescent pregnancy and childbirth. International Journal of Gynaecology and Obstetrics, 75, 111-121.

Walker, L. O., \& Montgomery, E. (1994). Maternal identity and role attainment: Long-term relation to children's development. Nursing Research, 43, 105-108.

Wiemann, C. M., Berenson, A. B., Pino, L. G., \& McCombs, S. L. (1997). Factors associated with adolescents' risk for late entry into prenatal care. Family Planning Perspectives, 29, 273-276.

Kristen S. Montgomery, $P h D, R N$, is a postdoctoral research fellow at the University of Michigan, School of Nursing, Ann Arbor.

Address for correspondence: Kristen S. Montgomery, PhD, RN, 39149 Debra Court, Clinton Township, MI 48038. E-mail: krismontgomery@botmail.com. 